MOTIVATION TO CHANGE IN EATING DISORDER PATIENTS:

A CONCEPTUAL CLARIFICATION ON THE BASIS OF SELF-DETERMINATION THEORY

Maarten Vansteenkiste, Bart Soenens \& Walter Vandereycken

Catholic University of Leuven, Belgium

Address for correspondence:

Maarten Vansteenkiste

Department of Psychology

Tiensestraat 102

3000 Leuven

Belgium

Tel: +3216325974

e-mail: Maarten.Vansteenkiste@psy.kuleuven.ac.be

Acknowledgements: The first and second author's contribution was supported by a grant of the Fund of Scientific Research, Flanders, Belgium.

RUNNING HEAD: Motivation in Eating Disorders 


\begin{abstract}
Objective: To critically review the different motivational frameworks that are applied in the study of eating disorders and to provide a more comprehensive conceptualization of motivation to change on the basis of self-determination theory. Method: The most important conceptualizations of motivation to change among eating disorder patients were identified.

Results: Eating disorder patients' motivation to change has been defined very differently, adding confusion to the field and preventing research from being cumulative. On the basis of self-determination theory we argue (a) that the quality of motivation to change is primarily reflected in the degree of internalization of change rather then by the intrinsic motivation to change; (b) that the internalization of change implies more than only the change being initiated from within the person (internal motivation) for it requires an acceptance of the personal importance of change; and (c) that, in addition to its quality, the quantity of motivation to change should be considered too. Discussion: These three conceptual issues are applied to the study of motivational dynamics in eating disordered patients.
\end{abstract}

KEY WORDS: Motivation, Self-determination Theory, Eating Disorders, Treatment 


\section{MOTIVATION TO CHANGE IN EATING DISORDER PATIENTS: A CONCEPTUAL CLARIFICATION ON THE BASIS OF SELF-DETERMINATION THEORY}

Motivational issues among eating disorder (ED) patients have been mentioned in the clinical literature since the first descriptions of anorexia nervosa in the $19^{\text {th }}$ century. With a few exceptions in previous decades (e.g., Engel \& Wilms, 1986), from the 1990s on the interest in motivational dynamics has exponentially increased, presumably because most clinicians and researchers agree with the contention that motivational deficits are pervasive among ED patients (Geller, 2002a; Mizes, 1998; Orimoto \& Vitousek, 1992;Touyz, Thornton, Rieger, George, \& Beumont, 2003; Vitousek, Watson \& Wilson, 1998; Vitousek, 2002). This increasing interest was following a general trend in the last decade during which motivational issues have captured the attention of various researchers in a variety of clinically domains, such as substance use disorders and sexual offense (Drieschner, Lammens, \& van der Staak, in press; Tierney \& McCabe, 2002).

In the present review, we will focus on the various motivational approaches that have been developed and used in an attempt to prevent ED patients from dropping out of treatment, to increase their active engagement in treatment and, hence, to improve the short-term and long-term outcome of therapy. In a first section, we will briefly discuss the most prominent approaches and analyze their conceptualization of motivation. It will be argued that, although these approaches have a lot in common, the literature seems to lack an overarching theoretical framework on motivational dynamics in ED. In a second section, we will introduce SelfDetermination Theory (Deci \& Ryan, 1985, 2000; Ryan \& Deci, 2000) as a candidate to offer such an overarching framework. More specifically, we will address three important issues in the conceptualization of motivation that may have specific relevance to motivation in ED. In the third section of this review, we will apply these three issues to the study of the approaches discussed in the first section, hereby attempting to improve our understanding of the motivation to change in ED patients.

\section{Motivation in the area of eating disorders}

Miller and Rollnick (1991) have defined motivation as "the probability that a person will enter into, continue, and adhere to a specific change strategy" (p. 19). Referring to this definition, motivation in ED patients is known to be often quite problematic and challenging to clinicians. Notorious, especially in anorexia nervosa, is the denial of illness and reluctance 
to enter therapy; bulimic patients on the other hand are known for their strong ambivalence and premature termination of treatment. Patients seem to share these features with substance abusers and addicts. From clinical practice with the latter group, Miller and Rollnick have developed the Motivational Interviewing (MI), which yielded cumulative insights into the best ways to help clients become pro-active participants in therapy. It was assumed that clients possess a powerful potential for change - that every client has strong inner resources to realize change. As a consequence, the task of the clinician is to evoke and strengthen this inner resourcefulness, thereby enhancing the intrinsic motivation to change already inherent in the individual. This inner growth process is facilitated when the clinician skillfully applies the following four key principles: expressing empathy, developing discrepancy, increasing self-efficacy, and rolling with resistance. MI has been shown to be effective in the domains of addiction treatment as well as for people with diabetes, hypertension, and HIV risk behaviors (Burk, Arkowitz, \& Dunn, 2002; Stotts, Schmitz, Rhoades, \& Garbowski, 2001). In addition, MI has been applied to the domain of ED at a theoretical level (Treasure \& Ward, 1997), and it has received some empirical confirmation (Killick \& Allen, 1997).

Inspired by MI, Vitousek, Watson, and Wilson (1998) have proposed the Socratic Method, well-known in cognitive therapy, as a tool to enhance motivation for change in ED patients. The approach involves being empathic towards the experiences of the patient, as reflected in the acknowledgement of the possible functions of the ED symptoms and the recognition that changing behavior is a difficult task. Furthermore, the aim of the Socratic Method is to offer an encouraging framework so that patients can reach conclusions on their own concerning the origin of their symptoms or the pros and cons of change. The clinician's task consists of helping patients to find their own solutions and to make their own decisions to change. The basic assumption is that, when a decision to change behavior is experienced as personally taken rather than being imposed by the therapist, the effects of the actual behavioral change will be more lasting. Vitousek, DeViva, Slay, and Manke (1995) developed a scale to measure concerns about change, and found that anorexics scored higher than bulimics and other pathological groups on most of the scales assessing resistance to change. The authors interpreted these results as evidence for the claim that anorexics demonstrate high levels of concern about the prospect of losing the perceived benefits of their egosyntonic symptoms.

Another popular model in the study of motivation among ED patients is the Transtheoretical Model of Change (TMC; Prochaska \& DiClemente, 1982; DiClemente, 1999). The primary goal of this model is to describe the different stages through which 
patients are going in their movement towards lasting change. People are said to move from precontemplation (not considering change at all), to contemplation (weighing the pros and cons of change), to preparation (getting ready to make the change), to action (making the change) and to maintenance (consolidating the positive change). This change process is considered as cyclical rather than linear in nature; thus, patients will move various times through the change cycle before achieving a state of sustained change. According to DiClemente (1999), clinicians can help patients to reach higher level stages by increasing their internal (or intrinsic) motivation as opposed to their external (or extrinsic) motivation to change. This is best achieved by applying the therapeutic principles and emphasizing the processes of change that match with the clients' particular stage (Prochaska \& DiClemente, 1982). Furthermore, each stage of change is said to be characterized by a particular balance between the pros and cons in change (Prochaska, 1994), and in moving from the precontemplation to the action phase patients' pros of change increase (strong principle), whereas their cons of change decrease (weak principle).

TMC has been applied in various domains (for an overview, see Prochaska \& Norcross, 2003) and, more recently, it was found to be useful in the domain of ED. Its principles, combined with ideas from MI, have inspired Treasure and Ward (1997) to develop the "motivational enhancement therapy", a specific therapeutic approach including a self-help guide. Moreover, a number or research groups (Blake, Turnbull, \& Treasure, 1997; Cockell, Geller, \& Linden, 2002; Serpell, Neiderman, Haworth, Emmanueli, \& Lask, 2003) have developed a decisional balance scale which assesses the pros and cons of change, and found that a shift from the precontemplation to the action phase among ED patients was associated with an increase in the pros of change, but not with a decline in the cons of change (Blake et al., 1997). Finally, questionnaires assessing ED patients' readiness to change have been developed (Beato Fernández \& Rodríguez Cano, 2003; Rieger, Touyz, \& Beaumont, 2002; Rieger, Touyz, Schotte, Beaumont, Russell, Clarke, Kohn, \& Griffiths, 2000), and were found to be predictive of treatment outcomes, such as weight gain (Rieger, 2000), improved body satisfaction and decreased drive for thinness (Gusella, Butler, Nichols, \& Bird, 2003), better therapeutic alliance and reduced frequency of binge eating (Treasure et al., 1999).

Though based on similar ideas, the Readiness and Motivation Interview (RMI; Geller, 2002a, b) deserves some special attention. A critical component of RMI involves the degree to which ED patients are making the change for themselves (internal motivation) or for other people (external motivation), because only internal motivation for change is said to produce lasting positive effects. The internal motivation for change is maximized by clinicians by 
being curious about and encouraging open discussions regarding the ambivalence of change and by extensively discussing the relevance of non-negotiables during therapy prior to its implication. The ED patient is seen as an active decision-maker, and every attempt to maximize responsibility for change in the hands of patients is encouraged. Thus, as most previously mentioned approaches, RMI primarily speaks to the manner in which treatment is delivered rather than to its specific therapeutic content. It has been shown that RMI scores at the beginning of treatment are predictive of drop-out, symptom change and relapse (Geller, 2002b; Geller, Cockell, \& Drab, 2001).

From the above descriptions, it becomes apparent that current motivational approaches to ED share a number of important common features.

1. They all seem to share the assumption that ED patients possess a powerful potential for change - that each patient is an active, growth-oriented organism with a natural tendency towards personal development and change, and that every patient has strong inner resources to realize such change. Thus, although ED patients might at some points in time even engage in self-destructive behaviors (Vitousek et al., 1998), most (if not all) of the described motivational theories seem to share the contention that patients possess the inner strengths to overcome their problems, given that they receive the necessary nutriments from their environment. Indeed, the task of the clinician is to evoke and strengthen this inner resourcefulness, facilitating the natural change process that is already inherent in the individual, rather than trying to impose motivation or "install" a change process.

2. All frameworks can be described as "content-free", i.e., they are primarily focused on the way therapists deal with ED patients rather than with the program or message being promoted (Geller, 2002a; Geller et al., 2003; Sheldon, Joiner, \& Williams, 2003; Miller \& Rollnick, 2002). This implies that they might be compatible with any type of treatment, including family therapy, cognitive behavior therapy, and pharmacotherapy (see Garner \& Garfinkel, 1997), because they are primarily concerned with the manner (i.e., collaborative or supportive versus confrontational) in which treatment interventions are delivered.

3. A further common characteristic of these motivational approaches is that the primary task of therapeutic intervention is to encourage patients to take the lead in the therapeutic process, so that any change effort is more willingly and choicefully enacted. The task of supporting patients and helping them to reach their own conclusions is not an easy one. Indeed, these approaches involve more than a patchwork of techniques that can be easily 
applied, but they imply a coherent and distinctive way of relating to others (Geller, 2002a; Vansteenkiste \& Sheldon, 2003; Vitousek et al., 1998). For example Miller and Rollnick (2002) argue that MI is a skillful clinical method that involves a certain "way of being with other people" (p. 41). Clinicians can not just try to sound reflective and empathic, they need to train themselves to think reflectively and to act empathetically. This might especially be true in the treatment of anorexic patients for a number of reasons. First, anorexics often display a critical and skeptical attitude towards others and are very sensitive to deception (Garner \& Bemis, 1982; Vitousek et al., 1998). As a consequence, any sign revealing a lack of sincere trust and honest interest and support from the side of the clinician might be taken as a signal to disrupt the relation. Second, it might be quite difficult to help anorexics to formulate their own answers because they have a strong inclination to seek external validation for their decisions and to conform to the opinion of others (Thompson \& Sherman, 1989; Vitousek, 1996). Third, because clinicians are very likely to encounter persistent resistance towards treatment, they have a greater likelihood of slipping into an authoritarian, "expert" position in which patients are implicitly or explicitly pushed to change (Vandereycken, 1993).

4. If the task for a clinician is to evoke the motivation to change present within each patient, it can be derived that motivation is not viewed as a static trait or disposition of the patient, but as a dynamic and fluctuating feature that can be affected by the environment (Geller, 2002a; Miller \& Rollnick, 2002). Instead of a personal characteristic, it is influenced by the interaction between patient and therapist (Miller, 1995). Such a view entails a profoundly different understanding of an ED patient's reluctance to change. Whereas "resistance" is sometimes viewed as an active subversion of therapy or as a conscious unwillingness to change from the side of the patient, it is now seen as being function of the interaction with the social environment. Thus, resistance becomes an interpersonal phenomenon that is in part elicited by (but also under control of) the clinicians' approach to the patient (Geller, 2002a). Specifically, resistance signals that the clinician is pushing the patient too strongly in a particular change direction, which is immobilizing rather than evoking the change present in each patient (Miller, Benefield, \& Tonnigan,1993).

However, despite the striking similarities among these approaches, a full comparison or integration of the various approaches is seriously hampered by the broad array of definitions used (e.g., internal, external, extrinsic, and intrinsic motivation). Apparently, most of these approaches fail to provide a comprehensive conceptualization of the motivational processes that might be responsible for the effectiveness of the proposed techniques, 
presumably because they have not always been linked to more general motivational frameworks. We consider it important to undertake such an endeavor, because the lack of a uniform terminology might be counterproductive for two reasons. First, it is likely to hinder an in-depth and integrated discussion of important motivational dynamics which have clinical utility. Providing a strong conceptual underpinning of motivational research represents a first step in building a meaningful motivational theory and developing an effective intervention program for promoting lasting behavioral change among ED patients. Second, the great variation in definitions prevents investigators from making meaningful comparisons between various empirical studies. Hence, we feel a growing need to define motivation precisely within the domain of ED. A framework that might be a valuable candidate to provide such an overarching conceptualization is the self-determination theory.

\section{Self-determination Theory}

In contrast to the approaches reviewed in the previous section, which have been developed primarily out of clinical practice, self-determination theory (SDT) was first examined in the laboratory before being tested in various applied domains as diverse as work, organization, unemployment, sports, therapy, and education (Deci \& Ryan, 2000; Ryan \& Deci, 2000a). The advantage of such an evolution is that investigators were primarily interested in the broad conceptualization of motivation before looking for its relevance for resolving motivational issues in applied settings such as the clinic. In doing so, SDT has pointed towards at least three critical issues in the conceptualization of motivation which might be relevant to the study of motivation in ED. First, SDT primarily focuses on the quality of motivation, claiming that two different types of high quality motivation can be distinguished: intrinsic motivation and internalized extrinsic motivation. Second, internal (in opposition to external) motivation can not be automatically equated with a high qualitative level of motivation. Although an activity might be initiated by the person rather than by external pressures, some types of internal motivation are less likely to yield lasting benefits because the behavioral regulation is insufficiently anchored within people's value-structures. Third, in addition to its quality, SDT also considers the quantity of people's motivation. These three issues are considered in more detail below.

\section{Intrinsic motivation and internalization}

SDT primarily focuses on the quality or the nature of motivation guiding people's activities. A first attempt to differentiate between qualitatively different types of motivation was made by Deci (1975), along with other motivational researchers at that time (e.g., Lepper, Greene \& Nisbett, 1973), who distinguished intrinsic from extrinsic motivation. Intrinsic 
motivation refers to doing an activity for its own sake (Deci, 1975; Ryan \& Deci, 2000b), i.e. because the activity is inherently enjoyable, satisfying, or fun. Intrinsic motivation is viewed as automatically self-determined, as the person's full capacities are willingly engaged in a self-catalyzing chain of activity (Ryan \& Deci, 2000a). In attributional terms, intrinsic motivation is represented by an internal perceived locus of causality because people perceive themselves as the origin or agent of their own actions. Perceived locus of causality (deCharms, 1968) refers to the degree to which people experience their behavior as selfinitiated or self-chosen rather than pressured and coerced. Because people's behavior willingly emanates from their self in the case of intrinsic motivation, their actions are said to be highly self-determined. Therefore, intrinsic motivation is depicted at the right side in Figure 1. This figure shows the self-determination continuum, which ranges from totally nonself-determined behaviors to highly self-determined behaviors. Each of the concepts in Figure 1 will be explained in the following paragraphs.

insert Figure 1 about here

In contrast to intrinsic motivation, extrinsic motivation is defined as the motivation to engage in an activity to obtain an outcome that is separate from the activity itself (Ryan \& Deci, 2000b). While the "reward" of the activity lies within the task-execution itself in the case of intrinsic motivation, the "reward" is situated outside the activity in the case of extrinsic motivation. Whereas intrinsic and extrinsic motivation were initially viewed as each other antipodes, later research (Ryan \& Connell, 1989) indicated that extrinsic motivation can vary in its degree of autonomy. Ryan, Connell and Deci (1985) used the term internalization to describe the degree to which non-enjoyable behaviors (i.e., extrinsically motivated behavior) are "taken in" within people's self-structures. To the extent that people have accepted the personal importance of the activity for their own, it provides the basis for an autonomous regulation of their extrinsically motivated behaviors. Indeed, when people have fully internalized the regulation of the activity, they will experience their behavior as an expression of their personal values and commitments, and they will engage in it with a sense of volition or autonomy. The issue of internalization sheds a first light on the quality of motivation. We will elaborate on this in the following section by considering whether promoting persons' internal motivation to engage in an activity adequately reflects the internalization process we are describing here. 


\section{From internal vs. external motivation to autonomous vs. controlled motivation}

There seems to exist considerable agreement concerning the definition of external motivation in both the motivational and clinical literature. When people's behavior is externally motivated they engage in the activity to obtain an external reward, to avoid a punishment or to meet external expectations. SDT also recognizes this type of motivation, suggesting that the regulation of the behavior has not been internalized at all in this case. Because people's actions are said to be highly non-self-determined, their behavior is characterized by an external perceived locus of causality (deCharms, 1968). Therefore, external regulation is placed at the left side in Figure 1.

Although various researchers have portrayed internal motivation as the opposite of external motivation (e.g., DiClemente, 1999, Geller, 2002a; Harter, 1981), SDT has maintained that not all types of internal motivation are created equally (Koestner, Losier, Vallerand, \& Carducci, 1996; Koestner \& Losier, 2002). Specifically, SDT holds that not all types of internal motivation, although being initiated from within the person rather than being caused by external forces, are likely to be experienced as truly autonomous or volitional. Indeed, people can well place themselves under pressure to engage in an activity. For instance, when people have buttressed their actions by self-esteem contingencies or by shame, guilt or anxiety, they have internalized the regulation of the activity, but they have not fully accepted the regulation of the activity as their own. This type of internalization is referred to as an introjected regulation and, in a sense, is only a partial internalization, because although the regulation of the activity resides now within the person, people still engage in the activity with a sense of pressure and stress. Therefore, introjected regulation is also characterized by an external perceived locus of causality and it is often combined with external regulation to form a controlled regulation composite.

Full internalization of the activity will only be achieved when people have succeeded in identifying with the regulation and value of a behavior and have more fully accepted it as their own. This type of extrinsic motivation is labeled identified regulation within SDT. When people foresee the personal importance of the activity, they will experience their behavior as a reflection of what they are and will experience their behavior as highly autonomous. Therefore, an identified regulation, as another type of internal motivation in addition to an introjected regulation, is not represented by an external but by an internal perceived locus of causality, and is often combined in empirical research with intrinsic regulation to form an autonomous motivation composite. 
Past research in various domains such as sports, unemployment, work, and education has shown that the advantages of autonomous (i.e., intrinsic and identified) versus controlled (i.e., introjected and externally regulated) forms of motivation are manifold, including enhanced well-being, lasting persistence, and higher performance (for overviews see Deci \& Ryan, 2000, 2002; Deci \& Vansteenkiste, 2003; Ryan \& Deci, 2000a; Vallerand, 1997). In addition, various studies in the domain of therapy and health care have confirmed the importance of autonomous vs. controlled motivation in predicting drop-out, lasting change and well-being among patients in clinical domains as diverse as alcohol cessation (Ryan, Plant, \& O’Malley, 1995), weight loss (Williams, Grow, Freedman, Ryan, \& Deci, 1996), exercise and diet programs for coronary artery disease and diabetes (Williams, Freedman, \& Deci, 1998), smoking cessation (Curry, Wagner, \& Grothaus, 1991; Williams \& Deci, 2001; Williams, Gagné, Ryan, \& Deci, 2002), medication adherence (Williams, Rodin, Ryan, Grolnick, \& Deci, 1998), adjustment to HIV+ and aids (Igreja et al., 2000) and dietary selfcare among diabetes patients (Senécal, Nouwen, \& White, 2000). Finally, as will be discussed in the next section, SD'T has also been applied to the examination of ED in a few studies (Frederick \& Grow, 1996; Simons, Vansteenkiste, Braet, \& Deci, 2003; Strauss \& Ryan, 1987; Williams, Grow, Freedman, Ryan, \& Deci, 1996) .

\section{Quantity of motivation}

In addition to the quality of motivation, SDT also considers, in line with various other motivational theories, such as expectancy-value theory (Eccles \& Wigfield, 2002; Feather, 1990) and self-efficacy theory (Bandura, 1989), people's amount or quantity of motivation to engage in a particular activity. The concept of a-motivation is introduced within SDT to convey the idea that some people feel discouraged and helpless with regard to their behavior, whereas others are hopeful and optimistic about successfully achieving an outcome. People displaying a low level of motivation are thus said to be a-motivated. Feelings of amotivation arise in people when they (a) feel incompetent to achieve an outcome, (b) experience a lack of contingency, and (c) do not value the behavior or outcome (Ryan \& Deci, 2000a). Typically, people will not engage in the activity in the case of amotivation, and if they do, their acting is likely to be prompted by external pressures. Therefore, amotivation is said to be highly nonself-determined, and is depicted at the left side in Figure 1.

When people feel amotivated with respect to their activity engagement, their behavior is said to be characterized by external perceived locus of control (Rotter, 1966; Skinner, 1995). The concept of locus of control reflects the degree to which people expect the outcome to follow in a reliable manner from their own intentional efforts and behaviors. 
When the locus of control is perceived as internal, people expect that the outcomes they are striving for are fully dependent upon their own behaviors, so that they display a high level of motivation. In contrast, when the locus of control is perceived as external, people have low expectations with regard to the behavior-outcome dependency. In the language of SDT, they are said to display a high level of amotivation.

Notably, various motivational theories tend to consider motivation as a unitary or unidimensional concept that exists in various amounts within individuals (Vansteenkiste, Lens, De Witte, \& Feather, 2003). However, according to SDT, it is of crucial importance to consider the quantity of motivation in conjunction with its quality. As such, the quantity of motivation to make the change is a different issue from the internalization of change. In other words, people's activities might be characterized by an internal perceived locus of control (Rotter, 1966), while being represented by either an internal or an external perceived locus of causality (deCharms, 1968). While the concept of locus of control pertains to the amount or quantity of motivation, the notion of locus of causality refers to the quality of motivation (Williams et al., 2002).

\section{Self-determination theory and eating disorders}

In this section, the question is raised how the previously discussed fundamental issues in the conceptualization of motivation can contribute to a better of understanding motivational dynamics in ED. Therefore, we attempt to apply each of these issues to the approaches reviewed in the first section, taking into account the following general remarks. Miller and Rollnick's (1991) definition of motivation was strongly criticized by Drieschner et al. (in press), because the intention and motivation to engage in specific problematic behavior is not defined independently of its behavioral manifestation. In fact, the definition becomes circular (Lens, 1997, Ryan \& Deci, 2000b), when motivation is inferred from the very behavior that is assumed to predict. Next, motivation to change always implies motivation to engage in a particular behavior, regardless of the type or quantity of motivation that guides this behavioral change. Thus, speaking about motivation for change is adequate as long as change refers to a well-defined problem (see Drieschner et al., in press; Dunn, Neighbours, \& Larimer, 2003; Treasure \& Schmidt, 2001). Nevertheless, because we are not focusing on one particular type of ED or one type of problematic behavior, we will use the more general label "motivation for change", keeping in mind that in empirical studies patients' motivation should be measured with regard to a particular behavior. 


\section{Intrinsic motivation to change or internalization of change?}

Both MI and TMC are aimed at increasing ED patients' intrinsic motivation for change. Miller and Rollnick (2002) argue that MI is "a client-centered, directive method for enhancing intrinsic motivation to change by exploring and resolving ambivalence" (p. 25; italics added). Similarly, within TMC (DiClemente, 1999), a distinction is made between "motivations that are internal to the individual (intrinsic) and those that are more external or environmental (extrinsic)" (p. 211, italics added). As such, it appears that Prochaska and DiClemente label every type of internal motivation intrinsic, while every type of environmentally produced motivation is said to be extrinsic. However, the question can be raised whether clinicians should focus on enhancing intrinsic motivation in the case of treatment of ED patients, a contention that is also shared by numerous researchers in other clinical domains (e.g., Battjes, Gordon, O’Grady, Kinlock, \& Carswell, 2003; Curry, Grothaus, \& McBride, 1997; De Leon, 1996; Downey, L., Rosengren, D. B., \& Donovan, 2001).

The definition of intrinsic motivation used within SDT and various other motivational theories (Reeve, 2002; Ryan \& Deci, 2000b) implies that clinicians should help ED patients to experience their changing behavior as fascinating and enjoyable. But how can a binge eater, for instance, who used to eat lots of sweets each day, now try to enjoy restricting or even stopping the intake of foods that have been linked with an immediately gratifying experience? And what kind of inherent pleasure can an anorexic girl experience while gaining weight? In contrast, trying to adopt a new lifestyle by quitting pleasurable behaviors might entail a considerable psychological cost for patients (Drieschner et al., in press; Meichenbaum \& Turk, 1987). As such, it is inappropriate to argue that the first and primary goal of treatment consists in enhancing the intrinsic motivation for change (Vansteenkiste \& Sheldon, 2003). In contrast, the task for the patient is to learn to execute a behavior that he/she would not do spontaneously. If one does not spontaneously engage in changing a behavior out of interest i.e., if one is not intrinsically motivated to change - there is only one option left: extrinsic motivation. Does this imply that some patients are doomed to fail in their endeavors from the start? Not at all. As outlined above, SDT claims that extrinsically motivated behavior can be experienced as autonomous or volitional as intrinsically motivated behavior. In order to execute a non-enjoyable behavior such as adopting a healthy eating pattern with a sense of volition and willingness, people need to learn to accept the personal importance of the changing behavior for their own self-structures. In other words, the regulation of the non- 
enjoyable activity needs to internalized gradually, so that people come to identify themselves with change.

In sum, we argue that the first goal of therapy in ED patients is not intrinsic motivation, i.e. to help them enjoy changing their old and maladaptive eating behaviors. The treatment is aimed at trying to foster the endorsement (i.e., internalization) of change, so that the change is experienced as a reflection of who people are. This does not imply that clinical frameworks, such as TMC and MI, are incompatible with SDT. All of the motivational approaches discussed earlier share substantial meta-theoretical assumptions with SDT regarding the goals of therapy and the pro-active nature of human beings (Vansteenkiste \& Sheldon, 2003). Likewise, consistent with SDT, DiClemente (1999) claims that "sustained change must be reinforced by incentives that are owned by the individual so that they become integrated into the life of the individual" (p. 211), whereas Miller and Rollnick (2002) also argue that clients need to elicit their own arguments for change, so that the motivation to change is more fully anchored within clients' self-structures. These statements nicely describe the process of internalization outlined within SDT.

\section{From internal vs. external to autonomous vs. controlled motivation}

There might exist considerable differences between ED patients in their levels of external motivation to enter treatment. Blake et al. (1997), Ward, Troop, Todd, and Treasure (1996) and Rieger (2000) reported that most of the bulimic patients were in the action phase at treatment entrance, whereas the majority of the anorexic patients were in the precontemplation or contemplation phases, presumably because only a minority of anorexic compared to bulimic patients enter therapy entirely of their own accord (Johnson, 1985). Indeed, because most anorexic patients feel pressured by family, relatives or friends to enter treatment, they are likely to report higher levels of external motivation to change, which might explain their higher levels of resistance to change (Vitousek et al., 1998).

The idea that ED patients should learn to internalize the regulation and value of the change has prompted some clinicians to argue that the goal of therapy consists of increasing patients' internal rather than their external motivation for change. For instance, one important feature of RMI (Geller, 2002a, b; Geller \& Drab, 1999) is to score the degree to which active work on symptom change from the side of the patient is done "for internal (i.e., for self) versus external (i.e., for others) reasons" (Geller, 2002b, p. 252; italics added). As mentioned above, DiClemente (1999) equated internal motivation with intrinsic motivation and opposed it to external or extrinsic motivation. 
SDT fully agrees with the contention that externally produced motivation is unlikely to yield lasting change effects. As most other clinically-oriented motivational models (Geller, Brown, Zaitsoff, Goodrich, \& Hastings, 2003), SDT argues that confrontational approaches in which the patient is pressured to accept expert-advise and is compelled to change old habits will not be beneficial, because it elicits resistance from the side of the patient (Miller, Benefield, \& Tonigan, 1993; Williams et al., 2002). In SDT-language, by pressuring patients to change an external regulation is induced within individuals, which manifests itself either through a furious defiance against (i.e., resistance) or passive compliance with these external, confrontational forces. However, the intended lasting change is unlikely to be produced, because patients are only acting in the presence of external pressures and, hence, have not internalized the change at all.

If enhancing the external motivation to change is counterproductive, this does not automatically imply that focusing on the internal motivation yields positive outcomes, as suggested by Geller (2002b) and DiClemente (1999). According to SDT, it is of crucial importance to consider the type of internal motivation: although patients' change efforts can be initiated by themselves, they don't always imply a full internalization of the change. Indeed, in the case of introjected regulation, internal pressures (such as feelings of guilt, shame, and anxiety) push patients into action. Although such types of internal regulation might be very powerful, it's unlikely to result in maintained changes, because the energy guiding the change behavior is more fragile and thus more easily eroded than in the case when people have fully internalized the change, as in the case of identification.

Having explained these different types of motivation, we can now re-interpret the suggestions made by DiClemente (1999) and Geller (2002b). First, should clinicians then avoid inducing extrinsic motivation, as suggested by DiClemente (1999)? Yes, in so far as they are producing an external regulation among their clients. No, in so far as they are helping patients to foresee the personal importance of change, so that they come to identify themselves with it. Second, should clinicians try to produce an internal motivation, as advocated by Geller (2002b)? Again, the answer is twofold: yes, to the extent that counselors help clients to fully concur with the reason for change; no, to the extent that clinicians are eliciting the introjects and internal obligations to change that are ready available within individuals. Interestingly, Vitousek et al. (1998) mentioned that anorexic patients in contrast to drugs abusers might experience "pride in being recognized as markedly different for the 'average' individual who struggles ineffectively with weight control” (p. 393). Similary, in Bruch's (1978) words anorexic patients "do not complain about their condition - on the 
contrary, they glory in it" (p. 145). Because they tend to see their disorder as an accomplishment rather than as an affliction (Bemis, 1983; Casper, 1982), they are unlikely to enter treatment to free themselves from their feelings of guilt and shame, which are the motivational source of an introjected regulation. As such, we would predict anorexics to display a lower level of introjected motivation to change than other ED patients.

The critical difference between introjected and identified motivation, which both represent two types of internal motivation, was recently confirmed in an experimental study in overweight children (Simons, Vansteenkiste, Braet \& Deci, 2003). Half of these children were encouraged in an autonomy-supportive fashion to follow the guidelines of the fourleafed clover, a simplified version of the food pyramid, by providing them opportunities for choice and self-initiative. Conversely, in a second condition, children were pressured in a subtle and implicit way to follow the guidelines over the four-leafed clover by using guiltinduction ("you might feel guilty for not doing so") and self-esteem contingent ("you might feel better about yourself if you would do so") practices. The goal of the latter counseling approach was to elicit the introjects that are readily available within individuals, while the former counseling approach would promote an identified regulation. Although any effort to follow the guidelines of the four-leafed clover would be initiated by the person in both cases (and not by external forces), the type of internal motivation guiding children's' change behavior was of a considerably different sort. An interesting pattern of results emerged. While children in both conditions adopted a more healthy life style, attended the organized diet-sessions and started to lose weight in the initial weeks following the experimental manipulation, these gains were only maintained after three weeks in the condition where an identified regulation was promoted. These findings suggest that differences between types of internal motivation matter; some overweight children might well push themselves into action, but not all types of internally induced motivation are likely to yield lasting positive changes. Treatment compliance will only be translated into effective and lasting change in so far as the decision to go into treatment is autonomously motivated rather than being imposed by guiltinducing internal pressures. In short, we argue that not every type of internal motivation is beneficial for the therapeutic process, as is sometimes implicitly assumed in a number of motivational approaches: autonomous, identified reasons for behavioral change are expected to be stronger predictors of lasting change than introjected reasons.

\section{Quantity of motivation}

As emphasized within SDT and various other motivational theories (e.g., Bandura, 1989; Eccles \& Wigfield, 2002), feeling efficacious or competent in undertaking a change 
effort has been found to predict a variety of important clinical outcomes. For instance, Williams, Grow, Freedman, Ryan and Deci (1996) demonstrated the importance of the quantity of motivation (in addition to its quality) in a longitudinal study among obese patients, showing that patients' level of perceived competence for losing weight (i.e., their quantity of motivation) positively predicted maintained weight loss assessed 23 months later. However, SDT emphasizes that the quality of motivation to change should be considered in addition to its quantity. Specifically, patients can be highly motivated to make a change because they feel the outcome lies within their personal control, but simultaneously they might not have internalized the personal importance of making the change. For example, an obese child might feel highly effective or competent in mastering his weight, while simultaneously feeling pressured by the dietitian to do so. Similarly, an anorexic patient might feel able to change her old, rigid behaviors, but she might simultaneously feel coerced by her family to do so.

Although the TMC seems to be very compatible with the concept of internalization of change and thus with the idea of the quality of motivation outlined within SDT, in some instances the theory seems to conceptualize patients' motivation primarily in terms of quantitative levels. For instance, in discussing the relevance of TMC for anorexics, Blake et al. (1997) suggest that their "preliminary findings suggest ways in which therapy can be targeted to maximize the level of motivation" (p. 186, italics added). Similarly, Dunn, Neigbors, and Larimer (2003) suggest that patients' stage allocation reflects their readiness to change, which "refers to the degree to which an individual is motivated to change problematic behaviors" (p. 306). The implicit assumption is that patients who are more motivated to engage in a particular change behavior will be situated in a higher phase. On the other hand, DiClemente (1999) noted that motivation for treatment does not always imply motivation for change, suggesting that patients might well be pressured by family members, peers or other forces to come to treatment but that they won't undertake any change effort (see also Battjes, Onken, \& Delany, 1999; De Leon, 1996). The opposite might also be the case: some patients may want to change their behavior without engaging in any formal treatment. Here the idea of motivation for self-help would be a most valuable domain of further research, especially in ED patients who are looking at outsiders (family members, therapists) as eventual "intruders" into their personal territory.

Patients can not only feel pressured by external or internal obligations to come into treatment, but also to make particular changes. For instance, some anorexic patients may start to gain weight, and give the impression that they feel more comfortable with themselves. To illustrate, in the study by Simons et al. (2003), clinicians, dietitians, and parents might get the 
impression that the children involved in the internal control condition are motivated and that their motivational strategies are effective, because they observe their patients or children acting. They look like being motivated to change their symptoms! The children do not only seem to be motivated for treatment, but also to make a change. In terms of TMC, the children find themselves in the action phase, one of the higher order phases in the change model. However, from a SDT-perspective, the critical question would not be to which extent patients find themselves in the action phase, but why they are in that phase. As outlined earlier, patients may make their initial attempts to change for very diverse underlying reasons, with some reasons being more internalized and, thus, being more probable to result in lasting change than other reasons. Notably, Ward, Troop, Todd, and Treasure (1996), in an attempt to apply the TMC model to the study of anorexia nervosa, made a similar observation, when noting that the majority of their patients appeared to be in the action stage, whereas their clinical impression was of a greater degree of ambivalence (see also Sullivan \& Terris, 2001). Also Rieger et al. (2000) seem to recognize that not all types of action are of equal value. They suggest that the small relationship between their anorexics' scores on the stage of change questionnaire and the amount of weight gain might be due to the fact that weight gain may have been strongly influenced by the phenomenon of "eating myself out of the hospital" (p. 394; see also Shelley, 1997).

Based on these findings and reasoning, the question could be raised whether the action phase really represents a higher change phase for all patients? In agreement with DiClemente (1999), we believe that motivation for change (in opposition to motivation for treatment) is important. However, based on SDT, we suggest that undertaking action will only be translated into maintained change if the change endeavor is enacted willingly, because being in the action phase in itself does not tell us anything about the underlying reason for undertaking action. These observations might especially hold for anorexic patients, who want to please others and to make a good impression. So, they might start to gain weight for controlled reasons (i.e., in order to get out of the hospital), but once they have left the treatment program, they will quickly lose their weight again.

\section{Conclusion}

Motivational issues have captured the attention of various researchers in the area of ED over the past years. However, together with this boom in interest, an increasing number of definitions has emerged, so that the field is lacking a uniform motivational terminology at present. The goal of our contribution was to point towards some critical issues in the conceptualization of motivation. In sum, we argued that an adequate analysis of motivational 
dynamics among ED patients might do well in taking into account (a) the degree to which the change has been internalized rather than being experienced as pleasurable or exciting (i.e., intrinsic motivation), (b) the degree to which the change represents a true expression of patients' personal values (identification) rather than being instigated by internal obligations (introjection), and (c) the quality of motivation to change next to the quantity (i.e., amotivation). We believe these conceptual considerations have both theoretical and practical utility in terms of building a meaningful theory on motivation to change, operationalizing more systematic and coherent research, and designing effective therapeutic interventions.

\section{REFERENCES}

Bandura, A. (1989). Human agency in social cognitive theory. American Psychologist, 44, $1175-$ 1184.

Battjes, R. J., Gordon, M. S., O'Grady, K. E., Kinlock T. W., Carswell, M. A. (2003). Factors that predict adolescent motivation for substance abuse treatment, Journal of Substance Abuse Treatment, 24, 221-232.

Blake, W., Turnbull, S., \& Treasure, J. (1997). Stages and processes of change in eating disorders: Implications for therapy. Clinical Psychology and Psychotherapy, 4, 186-191.

Bruch, H. (1978). The golden cage: The enigma of anorexia nervosa. Cambridge, MA: Harvard University Press.

Burke, B. L., Arkowitz, H., \& Durnn, C. (2002). The efficacy of motivational interviewing and its adaptations: What we know so far. In William R. Miller \& Stephen Rollnick (Ed.), Motivational interviewing. (pp. 217-250). New York London: Guilford Press.

Cockell, S. J., Geller, J., \& Linden, W. (2002). The development of a decisional balance scale for anorexia nervosa. European Eating Disorder Review, 10, 359-375.

Crisp, A.H. (1982). Anorexia nervosa: Let me be. London: Plenum Press.

Curry, S. J., Wagner, E. H., \& Grothaus, L. C. (1991). Evaluation of intrinsic and extrinsic interventions with a self-help cessation program. Journal of Consulting and Clinical Psychology, 59, 318-324.

Curry, S. J., Grothaus, L., \& McBride, C. (1997). Reasons for quitting: Intrinsic and extrinsic motivation for smoking cessation in a population-based sample of smokers. Addictive Behaviors, 22, 727-739.

deCharms, R. (1968). Personal causation: the internal affective determinants of behavior: New York: Academic Press.

Jeci, E. L. (1975). Intrinsic motivation. New York: Plenum. 
Deci, E. L., \& Ryan, R. M. (1985). Intrinsic motivation and self-determination in human behavior. New York: Plenum.

Deci, E. L., \& Ryan, R. M. (2000). The "what" and the "why" of goal pursuits: Human needs and the self-determination of behavior. Psychological Inquiry, 11, 227-268.

Deci, E. L., \& Ryan, R. M. (2002). Handbook of self-determination research. Rochester: The University of Rochester Press.

Deci, E. L., \& Vansteenkiste, M. (2003). Self-determination theory and basic need satisfaction: Understanding human development in positive psychology. Internal Research Report, University of Leuven, Belgium.

De Leon (1996). Integrative recovery: A stage paradigm. Substance Abuse, 17, 51-63.

DiClimente, C.C. (1999). Motivation for change: Implications for substance abuse treatment. Psychological Science, 10, 209-213.

Drieschner, K. H. , Lammers, S. M. M., van der Staak, C. P. F. (in press). Treatment motivation: An attempt for clarification of an ambiguous concept. Clinical Psychology Review.

Downey, L., Rosengren, D. B., \& Donovan, D. M. (2001). Sources of motivation for abstinence: A replication of the reasons for quitting questionnaire. Addictive Behaviors, 26, 79-89.

Dunn, E. C., Neigbors, C., \& Larimer, M. (2003). Assessing readiness to change binge eating and compensatory behaviors. Eating Behaviors, 4, 305-314.

Eccles, J. S., \& Wigfield, A. (2002). Motivational beliefs, values, and goals. Annual Review of Psychology, 53, 109-132.

Engel, K., \& Wilms, H. (1986). Therapy motivation in anorexia nervosa: Theory and first empirical results. Psychotherapy and Psychosomatics, 46, 161-170.

Feather, N. T. (1990). The psychological impact of unemployment. New York: Springer-Verlag. Feld, R., Wooside, D. B., Kaplan, A. S., Olmsted, M. P., \& Carter, J.C. (2001). Pretreatment motivational enhancement therapy for eating disorders: A pilot study. International Journal of Eating Disorders, 29, 393-400.

Beato-Fernández, L., \& Rodríguez-Cano, T. (2003). Attitudes towards change in eating disorders (A.C.T.A.). Actas Españolas de Psiquiatría, 31, 111-119.

Frederick, C. M., \& Grow, V. M. (1996). A mediational model of autonomy, self-esteem and eating disordered attitudes and behaviors. Psychology of Women Quarterly, 20, 217-228.

Garner, D.M., \& Garfinkel, P.E. (Eds.)(1997). Handbook of treatment of eating disorders $\left(2^{\text {nd }}\right.$ edition). New York: Guilford Press.

Geller, J. (2002a). What a motivational approach is and what a motivational approach isn't: Reflections and responses. European Eating Disorders Review, 10, 155-160. 
Geller, J. (2002b). Estimating readiness for change in anorexia nervosa: Comparing clients, clinicians, and research assessors. International Journal of Eating Disorders, 31, 251-260. Geller, J., Brown, K. E., Zaitsoff, S. L., Goodrich, S., \& Hastings, F. (2003). Collaborative versus directive interventions in the treatment of eating disorders: Implications for care providers. Professional Psychology: Research and Practice, 34, 406-413.

Geller, J., Cockell, S., \& Drab, D. L. (2001). Assessing readiness for change in the eating disorders: The psychometric properties of the readiness and motivation interview. Psychological Assessment, 13, 189-198.

Geller, J., \& Drab, D. L. (1999). The readiness and motivation interview: A symptom-specific measure of readiness for change in the eating disorder. European Eating Disorder Review, 7, 259-287.

Gusella, J., Butler, G., Nichols, L., \& Bird, D. (2003). A brief questionnaire to assess readiness to change in adolescents with eating disorders: Its applications to group therapy. European Eating Disorder Review, 11, 58-71.

Igreja, I., Zuroff, D. C., Koestner, R., Saltaris, C., Brouilette, M.-J., \& Lalonde, R. (2000). Applying self-determination theory to the prediction of distress and well-being in guay men with HIV and AIDS. Journai of Applied Social Psychology, 30, 686-706.

Johnson, C. (1985). Initial consultation for partients with bulimia and anorexia nervosa. In D. M. Garner \& P. E. Garfinkel (Eds.), Handbook of psychotherapy for anorexia nervosa and bulimia (pp. 19-51). New york: Guilford Press.

Killick, S., \& Allen, C. (1997). "Shifting the balance" - motivational interviewing to help behavior change in people with bulimia nervosa. European Eating Disorder Review, 5, 33-41.

Koestner, R., \& Losier, G. F. (2002). Distinguishing three ways of being highly motivated: A closer look at introjection, identification, and intrinsic motivation. In E. L. a. R. R. M. Deci (Ed.), Handbook of self-determination research. (pp. 101-122). Rochester, U.S.A.: University of Rochester Press.

Koestner, R., Losier, G. F., Vallerand, R. J., \& Carducci, D. (1996). Identified and introjected forms of political internalization: Extending self-determination theory. Journal of Personality and Social Psychology, 70, 1025-1036.

Lens, W. (1997). Studiemotivatie [Motivation for studying]. De Psycholoog, 32, 53-59.

Lepper, M. R., Greene, D., \& Nisbett, R. E. (1973). Undermining children's intrinsic interest with extrinsic rewards: A test of the "overjustification" hypothesis. Journal of Personality and Social Psychology, 28, 129-137.

Meichenbaum, D., \& Turk, D.C. (1987). Facilitating treatment adherence: A practitioner's 
guidebook. New York: Plenum.

Miller, W. R. (1985). Motivation for treatment: A review with special emphasis on alcoholism. Psychological Bulletin, 98, 84-107.

Miller, W. R., Benefield, G., \& Tonigan, J. S. (1993). Enhancing motivation for change in problem drinking: A controlled comparison of two therapist styles. Journal of Consulting and Clinical Psychology, 84, 455-461.

Miller, W. R., \& Rollnick, S. (1991). Motivational interviewing: preparing people to change addictive behavior. New York: Guilford Press.

Miller, W. R., \& Rollnick, S. (2002). Motivational interviewing. New York: Guilford Press. Mizes, J. S. (1998). Neglected topics in eating disorders: Guidelines for clinicians and researchers. Clinical Psychology Review, 18, 387-390.

Orimoto, L., \& Vitousek, K.B. (1992). Anorexia nervosa and boulimia nervosa. In P.H. Wilson (Ed.), Principles and practice of relapse prevention (pp. 85-127) New York: Guilford Press. Prochaska, J. O. (1994). Strong and weak principles for progressing from precontemplation to action on the basis of twelve problem behaviors. Health Psychology, 13, 47-51.

Prochaska, J. O., \& DiClemente, C. C. (1982). Transtheoretical therapy: Toward a more integrative model of change. Psychotherapy: Theory, Research, and Practice, 19, 276-288.

Prochaska, J. O., \& Norcross, J. C. (2003). Systems of psychotherapy. Australia, Canada, Mexico, Singapore, Spain, United Kingdom, United States: Thomson, Brooks/Cole.

Reeve, J. (2002). Self-determination theory applied to educational settings. In Deci, E. L. \& Ryan, R. M. Handbook of self-determination Research. Rochester, NY: University of Rochester Press. Rieger, E. (2000). The development of an instrument to assess readiness to recover in anorexia nervosa. Unpublished doctoral dissertation, University of Sidney, Sydney, Australia.

Rieger, E., Touyz, S., Schotte, D., Beumont, P., Russell, J., Clarke, S., Kohn, M., \& Griffiths, R. (2000). Development of an instrument to asessess readiness to recover in anorexia nervosa. International Journal of Eating Disorders, 28, 387-396.

Rieger, E., Touyz, S. W., \& Beumont, P. J. V. The anorexia nervosa stages of change questionnaire (ANSOCQ): Information regarding its psychometric properties.

Rotter, J. B. (1966). Generalized expectancies for internal versus external control of reinforcement. Psychological Monographs, 80, Whole No. 609

zyan, R. M., \& Connell, J. P. (1989). Perceived locus of causality and internalization: Examining reasons for acting in two domains. Journal of Personality and Social Psychology, 57, 749761.

-yan, R. M., Connell, J. P., \& Deci, E. L. (1985). A motivational analysis of self-determination and 
self-regulation in education. In C. Ames and R. E. Ames (Eds.), Research on motivation in education: The classroom milieu. Bew Tirj: Academic Press.

Ryan, R. M., \& Deci, E. L. (2000a). Self-determination theory and the facilitation of intrinsic motivation, social development and well-being. American Psychologist, 55, 68-78.

Ryan, R. M., \& Deci, E. L. (2000b). Intrinsic and extrinsic motivations: Classic definitions and new directions. Contemporary Educational Psychology, 25, 54-67.

Ryan, R. M., Plant, R. W., \& O'Malley, S. (1995). Initial motivations for alcohol treatment: Relations with patient characteristics, treatment involvement and drop-out. Addictive Behaviors, 20, 279-297.

Senécal, C., Nouwen, A., \& White, D. (2000). Motivation and dietary self-care in adults with diabetes: Are self-efficacy and autonomous self-regulation complementary or competing constructs? Health Psychology, 19, 452-457.

Serpell, L., Neiderman, M., Haworth, E., Emmanueli, F., \& Lask, B. (2003). The use of Pros and Cons of Anorexia Nervosa (P-CAN) Scale with children and adolescents. Journal of Psychosomatic Research, 54, 567-571.

Sheidon, K.M., Williams, G., \& Joiner, T. (2003). Motivating health: Applying self-determination theory in the clinic. Yale: Yale University Press.

Simons, J., Vansteenkiste, M., Braet, C., \& Deci, E. L. (2003). Promoting Maintained Weight Loss through Healthy Lifestyle Changes among Obese Children: An Experimental Test of SelfDetermination Theory. Internal Research Report, University of Leuven, Belgium.

Skinner, E.A. (1995). Perceived control, motivation, and coping. Sage, Thousand Oaks: CA. Stotts, A. L., Schmitz, J. M., Rhoades, H. M., \& Garbowski, J. (2002). Motivational interviewing with cocaine-dependent partients: A pilot study. Journal of Consulting and Clinical Psychology, 69, 858-862.

Strauss, J., \& Ryan, R. M. (1987). Autonomy disturbances in subtypes of anorexia nervosa. Journal of Abnormal Psychology, 96, 254-258.

Thompson, R. A., \& Sherman, R. T. (1989). Therapist erros in treating eating disorders: Relationship and process. Psychotherapy, 26, 62-68.

Tierney, D. W., McCabe, M. P. (2002). Motivation for behavior change among sex offenders: A review of the literature. Clinical Psychology Review, 22, 113-129.

Touyz, S., Thornton, C., Rieger, E., George, L., \& Beumont, P. (2003). The incorporation of stage of change model in the day hospital treatment of patients with anorexia nervosa. European Child and Adolescent Psychiatry, 12,65-71.

reasure, J., \& Smidt, U. (2001). Reading, willing, and able to change: Motivational aspects of the 
assessment and treatment of eating disorders. European Eating Disorder Review, 9, 4-18.

Treasure, J., \& Ward, A. (1997). A practical guide to the use of motivational interviewing in anorexia nervosa. European Eating Disorder Review, 5, 102-114.

Treasure, J. L., Katzman, M., Schmidt, U., Troop, N., Todd, G., \& de Silva, P. (1999). Engagement and outcome in the treatment of bulimia nervosa: first phase of a sequential design comparing motivation enhancement therapy and cognitive behavioural therapy. Behaviour Research and Therapy, 37, 405-418.

Vallerand, R.J. (1997). Toward a hierarchical model of intrinsic and extrinsic motivation. In M. P. Zanna (Eds.), Advances in experimental social psychology. (pp. 271-360). San Diego: Academic.

Vandereycken, W. (1993). Naughty girls and angry doctors: Eating disorder patients and their therapists. International Review of Psychiatry, 5, 13-18.

Vansteenkiste, M., Lens, W., De Witte, H., \& Feather, N.T. (2003). Understanding unemployed people's job search behavior, unemployment experience and well-being: A comparison of exepctancy-value theory and self-determination theory. Internal Research Report, University of Leuven, Belgium.

Vansteenkiste, M., \& Sheldon, K. M. (2003). "There is nothing more practical than a good theory": Integrating motivational interviewing and self-determination theory. Internal Research Report, University of Leuven, Belgium.

Vitousek, K. M. (1996). The current status of cognitive-behavioral models of anorexia nervosa and bulimia nervosa. In P. M. Salkovskis (Ed.), Frontiers of cognitive therapy. (pp. 383-418). New York: Guilford Press.

Vitousek (2002). Cognitive-behavioral therapy for anorexia nervosa. In C. G. Fairburn and K. D. Brownell (Eds.), Eating Disorders and Obesity: A comprehensive handbook (pp. 308-313). The Guiford Press, New York, London.

Vitousek, K. B., De Viva, J., Slay, J., \& Manke, F. (1995). Concerns about change in the eating and anxiety disoders. Paper presented at the 103rd Annual Convention of the American Psychological Association, New York.

Vitousek, K., Watson, S., \& Wilson, G. T. (1998). Enhancing motivation for change in treatmentresistant eating disorders. Clinical Psychology Review, 18, 391-420.

Ward, A., Troop, N., Todd, G., \& Treasure, J.L. (1996). To change or not to change-How is the question? British Journal of Medical Psychology, 69, 139-146.

Nilliams, G. C., \& Deci, E. L. (2001). Activating patients for smoking cessation through physician autonomy support. Medical Care, 39, 813-823. 
Williams, G. C., Freedman, Z. R., \& Deci, E. L. (1998). Supporting autonomy to motivate patients with diabetes with glucose control. Diabetes Care, 2, 1644-1651.

Williams, G. C., Gagné, M., Ryan, R. M., \& Deci, E. L. (2002). Facilitating autonomous motivation for smoking cessation. Health Psychology, 21, 40-50.

Williams, G. C., Grow, V. M., Freedman, Z. R., Ryan, R. M., \& Deci, E. L. (1996). Motivational predictors of weight-loss and weight loss-maintenance. Journal of Personality and Social Psychology, 70, 115-126.

Williams, G. C., Minicucci, D. S., Kouides, R. W., Levesque, C. S., Chirkov, V. I., Ryan, R. M., \& Deci, E. L. (2002). Self-determination, smoking, diet and health. Health Education Research: Theory and Practice, 17, 512-521.

Williams, G. C., Rodin, G. C., Ryan, R. M., Grolnick, W. S., \& Deci, E. L. (1998). Autonomous regulation and long-term medication adherence in adult outpatients. Health Psychology, 17, 269-276. 
Figure 1

Schematic Relation of the Five Types of Motivation according to SDT

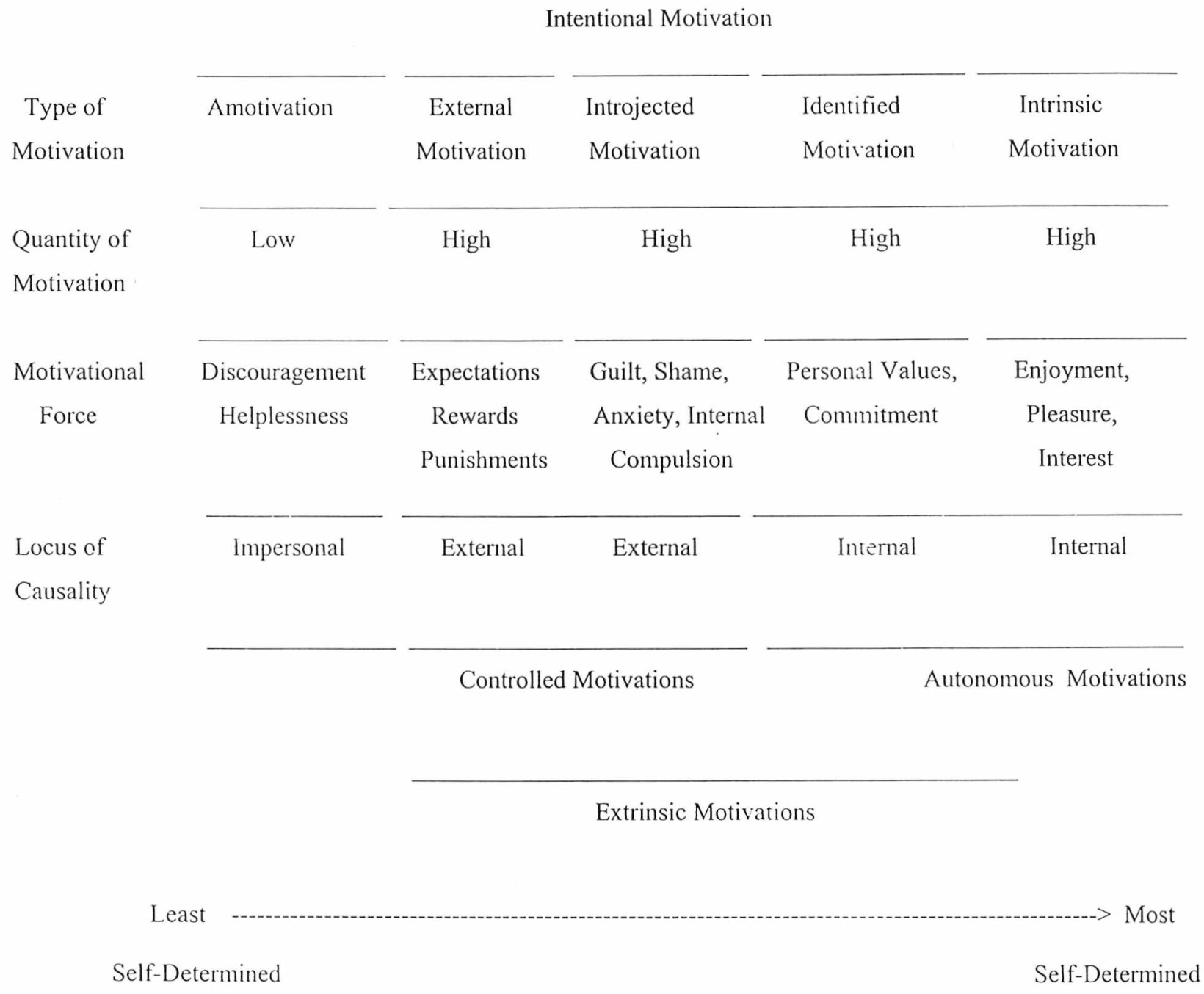

